\title{
Cryosphere and Spatial uniformitarianism: a new rule for Earth and Planetary Sciences
}

\author{
Wojciech Dobiński ${ }^{1}$ \\ ${ }^{1}$ University of Silesia, Faculty of Earth Sciences, ul. Będzińska 60, 41-200 Sosnowiec, Poland. \\ * Correspondence: wojciech.dobinski@us.edu.pl
}

\begin{abstract}
The lack of a uniform approach in Earth and planetary science is apparent in the current levels of inconsistency found within the research itself, the data analysis and the interpretation of results. Thus, data interpretation differ depending on whether the study refer to Earth conditions or from space. These differences are particularly pronounced for cryosphere studies, where geocentric approaches remain within ice research and its application in analogical studies. Here, the principle of spatial uniformitarianism is presented, to allow for a definitive departure from geocentrism and a proper understanding of the role of ice within both the Earth and celestial bodies. At the practical level, it may affect several geo-scientific disciplines currently inconsistent and bridging the gap among them. This rule is universal and complements the Hutton-Lyell 1795/1830 principle.
\end{abstract}

Keywords: cryosphere; ice; uniformitarianism; new rule.

\section{Introduction}

Geological uniformitarianism, also known as actualism, was first mentioned by Charles Lyell in 1830 in his Principles of Geology, and further developed by James Hutton in 1795 within the Theory of Earth. The term was originally coined by William Whewell in 1832, in his review of Lyell's Principles of Geology [1]. However, the concept continues to be discussed and its importance and impact on science should not to be underestimated. More recent reviews of the term included that of M. Romano [1], who discusses uniformitarianism in modern Earth science, and the historical connotations attributed to the term over time. The general principle of methodological uniformitarianism assumes no spatial or temporal variation of natural laws. In particular he discusses the potential for spatial variability.

The term uniformitarianism is mainly discussed in relation to its application to Earth conditions. Here, the discussion will be extended to cover extraterrestrial bodies, inaccessible for empirical study by Earth scientists until relatively recently. Actually, the number of studies describing the geological structure of other celestial bodies have been steeply increasing over the past decade, and can be now counted by the thousands. In fact, the approaches used within Earth science have been successfully applied to space research, with geological and geomorphological processes occurring on Earth being also identified on extraterrestrial rocky surfaces. Consequently, there are currently no reasons to limit the applicability of geological, hydrological or geomorphic systematics to the terrestrial conditions only [2]. Scientific universality will also allow for the development of new concepts applicable to space science.

Universalism, however, does face certain cognitive barriers, particularly those derived from human perceptions, and habit. Whilst technical barriers can be overcome with the development of new technologies, cognitive barriers requires of conceptual shifts. More importantly, cognitive barriers tend to have an exceptional impact on the development of scientific disciplines, yet are frequently not perceived as such. For example, the usage of the prefix geo- (meaning 'referring to Earth') to refer to the surface or interiors of planets covered by space science has been seldom contested. A 
similar inconsistency is found when we refer to Martian geology [3]. Yet, the use of these terms implies a unidirectional application of Earth geology concepts and systematics to other celestial bodies, which is particularly controversial as the Earth is always used as a reference to the rest of the cosmos, not vice versa [4]. This directionality implies a geocentric approach to planetary science, even though the Earth still remains as an extremely rare cosmological exception.

Copernicus published his De revolutionibus orbium cœlestium: libri VI in 1543, nearly 475 years ago, yet the geocentric perception of the universe somewhat remains even at the highest scientific level. A clear example is the use of sunset or sunrise, reasonable terms as common language, but similar way of thinking is used in space and planetary science and further reflecting the overarching dominance of geocentric approaches and perceptions [5]. This is particularly important for those studies where Earth is used as analogue for other planetary processes. However, it remains an open question whether the analogy can be reversed, and whether planetary processes can be used as analogue processes for Earth. Strong tendencies to consider Earth as the guide planet would be main limiting factor to this approach [5].

In the same way geological uniformitarianism has become apparent, here I argue that the principle of uniformitarianism, which has so far been referred to as processes acting in time, should be modified and applied in parallel to processes on celestial bodies. This, in turn, will be consistent with above mentioned reference to spatial and time invariability of natural laws.

\section{Water and Ice}

Water represents a particularly good example to illustrate the need to reserve the use of analogues and the requirement to extend in space geological uniformitarianism, from planetary science to Earth, instead of otherwise. To date, Earth is the only planet where water is known to occur in its three states, gas, liquid and ice, simultaneously. Unfortunately, water is rarely defined as a threephase substance (as defined by the Encyclopedia Britannica), but most often is mistakenly defined solely as a liquid. 


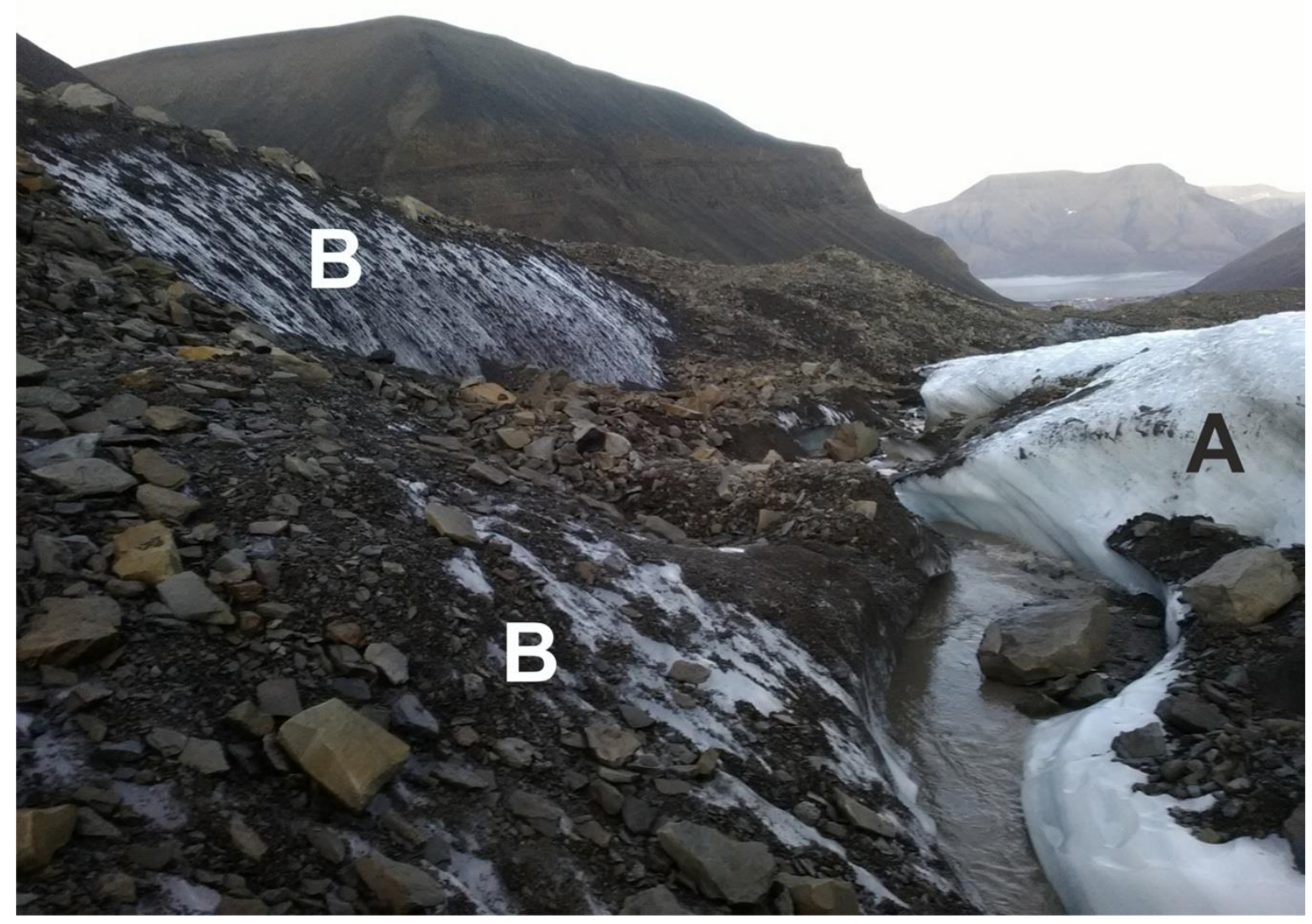

Figure 1: Ice as a monomineral sedimentary and metamorphic rock which shows its geological (tectonic) structure (layering, folding, faulting etc ) in its active part (A); and inactive ice covered by thin morainic deposits (B). Thermal and chemical erosion of liquid water creating a river channel which dividing glacial lithosphere on part A and B. (western margin of the Longyearbreen, Spitsbergen 78o19'N, 15o52,E, October 1, 2017, ca. 300m a.s.1.).

The widespread identification of water as a liquid leads to an equally erroneous perception of ice [6-8], which is commonly defined as frozen water. Water is common is the Solar System, and therefore, its study must be considered as a sub-discipline of Earth and Planetary Science. On the other hand, ice has been classified as a mineral [9], as it shares all the characteristics of rock-forming minerals [9,10], (http://rruff.info/ima/) and is able to create monomineral rocks [9,-11] (Fig.1). Yet, ice is most frequently considered as part of the hydrosphere [12], despite the characteristically lithosphere processes associated to ice, including folding, faulting, geomorphological processes in the creation of supraglacial river channels, cryokarst processes, snow-dune formation and many other processes (Fig. 1.). Ice unique characteristics compared to other types of rock is in fact apparent when we apply the same geological criteria to it, as it shows very specific properties, for example, its melting point is very low, as that of mercury, and it floats on water like pumice [5, 6, 13]. Indeed, the term iceberg (ice-mountain) to refer to floating glacial ice fragments is correct in the literal sense, as they represent floating parts of the icy-lithosphere (Fig. 2). 


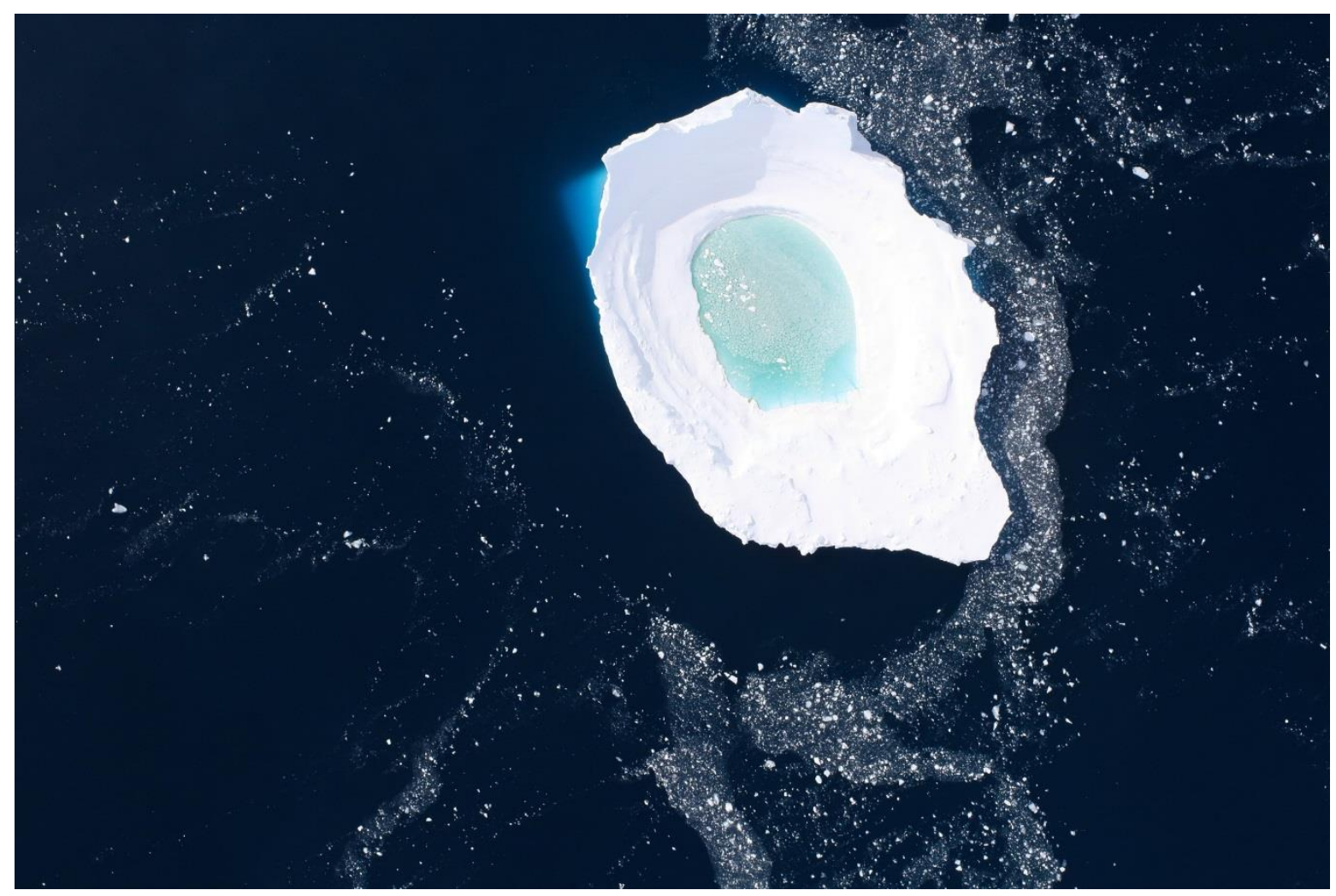

Figure 2: Image shows complexity hydrosphere / lithosphere relationship: iceberg floating on the sea, top on it freshwater reservoir created by melting of ice as well as meteoric water, covered by pancake ice and small growlers. Similar water reservoirs in a shape of ponds, lakes, rivers and englacial hydrological system exists in glaciers and ice-sheets. Small icebergs and growlers around iceberg creates on sea-water specific surface cover analogous to the pumice surface created by subsea volcanic eruption. Image obtained during UAV (PW-ZOOM) flight mission on November 16, 2015, altitude 357,1 m, iceberg location: sea water of Admirality Bay, King George Island, South Shetland Islands: 62o09'11"S 58027'17"W. Courtesy: dr Anna Zmarz, A novel approach to monitoring the impact of climate change on Antarctic ecosystems, project "MONICA" POL -NOR/197810/84/2013.

On the other hand, many earth-scientists still consider ice as a component of the hydrosphere, identifying ice as a synonym of water in general. This position suggests that ice-rock is unstable, ephemeral and easily subjected to thawing. This is why ice-sheets and glaciers are commonly, but erroneously, referred to as the largest freshwater reservoirs containing $68.7 \%$ of all fresh water resources on Earth [12], (Fig. 3). Antarctica contains $27 \times 10^{6} \mathrm{~km}^{3}$ of ice [13]; however, this water is not on liquid form and the continent is also the driest in the world. In a practical sense, the biggest water reservoir in the world would is useless to extinguish a fire in an Antarctic research stations highlighting ice on dryland as one of the most misunderstood issues in Earth sciences [14,15]. 


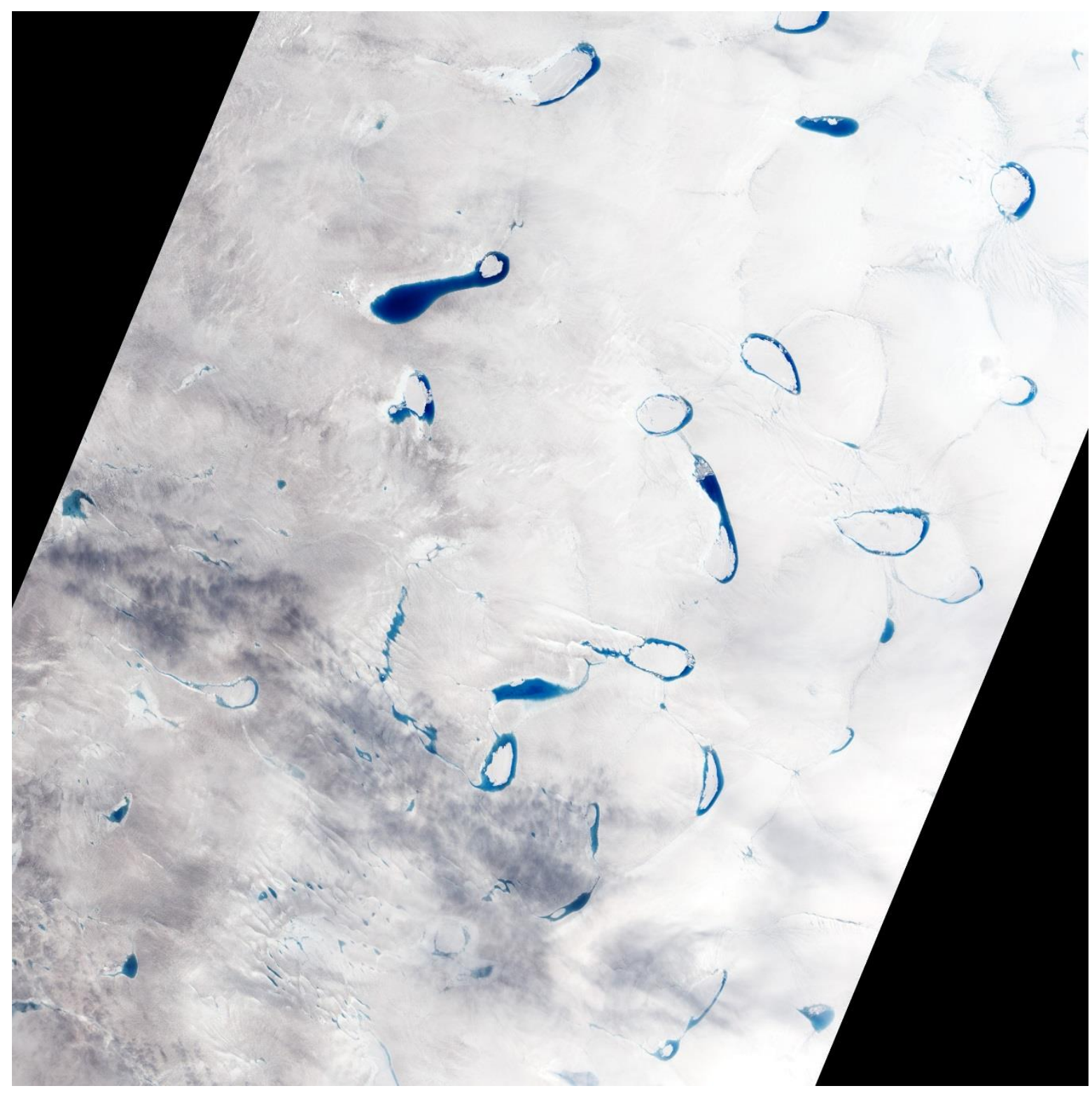

Figure 3: Glacial ice-dome of southwestern Greenland (near Disko Bay) at the beginning of ablation period (image was acquired on July 4, 2010). On the surface of ice-rock real reservoirs of water still partly covered by congelation ice are visible. The center of the image coordinates: $68^{\circ} 91^{\prime} \mathrm{N}$ and $48^{\circ} 54^{\prime} \mathrm{W}$. Courtessy of NASA (www.nasa.gov). Analogous reservoirs for liquid are found on Titan

Ice is believed to be involved in the global water cycle, and hence considered part of the hydrosphere [12]. However, this statement is also incorrect for two reasons. First of all, because in the water cycle in its nature is identified with fluids i.e., with liquid/vapour circulation above, over and within lithosphere, however, ice is a brittle solid and as a mineral and rock it constitutes the part of the lithosphere, not circulating in the same way than water in its fluid states. Secondly, ice actually hinders the circulation of liquid water by solidifying it (Fig. 4 and 5), not by retention in its hydrological sense - as it is in case of liquid water - for a shorter, or even very long time as it is in case of glaciers and ice-sheets. During the Cryogenian global glaciation at least ca. $30 \mathrm{Myr}$, the ice cover grew through a processes of runaway albedo feedback, which caused the world ocean to be virtually covered by sea ice, although the continental ice cover was thin and patchy because the freezing ie. solidification of water at the Earth surface virtually eliminated the hydrologic cycle [16]. It is also worth noticing that the Antarctic Ice-sheet and all the glaciers were not created by the freezing of water, but through geological processes such as sedimentation, diagenesis, 
metamorphism and creeping of snow transformed into glacial ice. In the absence of these processes, glaciers will simply not form. In this context, ice cannot be considered a reservoir of water, and hence a component of the hydrosphere, as much as we do not say that magmatic rocks are reservoir of magma. The imprecise concept of glacier flow, where the term flow is that from the physics for fluids, that is, gases and liquids, is used to describe glacial motion, while due to obvious differences glaciers defined as solids should have different and exclusive term for their motion. For example,

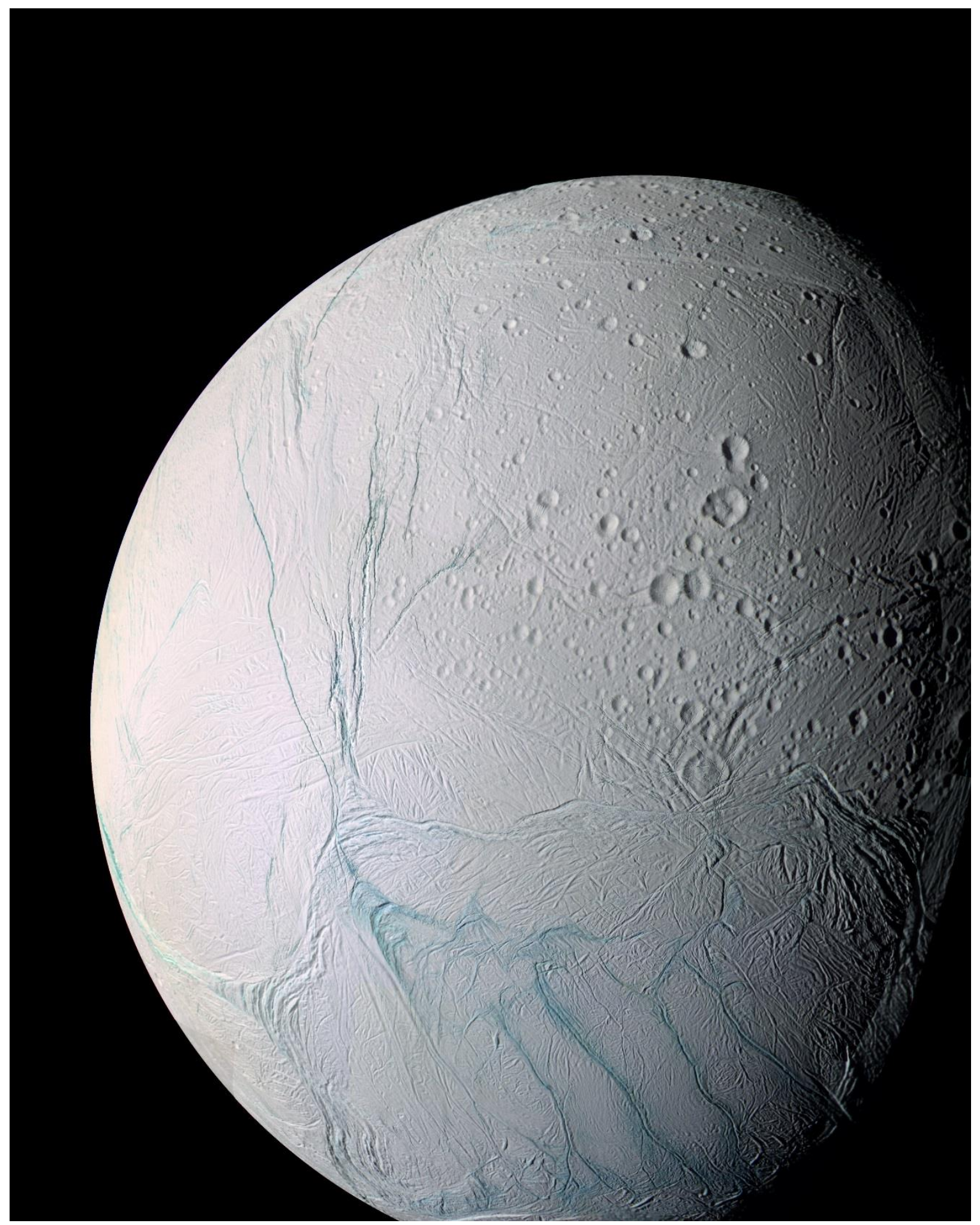

Figure 4: Surface structure of the Saturns sixth largest satellite, Enceladus is composed mostly of nearly pure water ice. Its internal activity has resulted in several episodes of resurfacing, ridge building, folding, and faulting which are visible on the surface (Brown et al. 2006). The mosaic was created from 
21 false-color images taken during the Cassini mission on March 9 and July 14, 2005 courtesy of Jet Propulsion Laboratory, (www.jpl.nasa.gov).

creep is used often as synonymous for flow. Indeed, using the same term to describe the movement of water inside the glaciers and the motion of the glacier itself is inaccurate, as we are referring to the motion of solids and liquids, even when we recognize the specific visco-plastic properties of the glacier movement [17].

A specific paradox is the universal naming and classifying of Antarctica as a continent. Only the inclusion of the Antarctic ice cover as part of the lithosphere justifies the use of such terminology. Otherwise, Antarctica is virtually covered by water, yet we do not refer to is as a part of the ocean. Indeed, if Antarctica was to be recognized as a rocky substrate covered by hydrospheric component, we would talk about an archipelago identical (also in genetic sense) to that in the Canadian Arctic. Nearly half of the Antarctic rocky base $\left(44.7 \%\right.$ or $\left.5.50 \times 10^{6} \mathrm{~km}^{2}\right)$ is below sea level [13], covered with an icy-hydrosphere. A similar situation is found with the border of Antarctica, with approximately $74 \%$ of it presenting floating ice shelves or outlet glaciers [18]. Ice shelves cover an area of ca. 1,561 million $\mathrm{km}^{2}$ oceanic waters [19]. In this case, then, it is obvious that clearly identifying ice as part of the lithosphere or the hydrosphere will determine the very nature of Antarctica. Compared to total land cover on Earth, $149 \times 10^{6} \mathrm{~km}^{2}$, the area of Antarctica is a significant size, amounting to almost $14 \times 10^{6} \mathrm{~km}^{2}$ with $95 \%$ of its border length being ice. The ice over the Arctic Ocean can be considered the same one: "Where land turns to sea and sea turns to land through processes of ice formation and ice melt, new territory is perpetually formed and dissolved, creating new questions over ownership, political control and rights over resources" [20]. Incorporating ice into the lithosphere will also allow for a uniform treatment of the cryospheric components. Up to now, glaciers and permafrost studies have been conducted separately. Glacial ice could not be identified within the permafrost, since the concept of permafrost was referred exclusively to the glacier-free lithosphere, even if the existence of both seems to be frost-dependent. At least the upper part of polithermal glaciers is made of cold ice and remains entirely frozen due to the atmospheric conditions above. This layer is analogous to the frozen layer in the glacial forefield traditionally identified to permafrost [21]. Therefore, in the same way we can distinguish theoretically and empirically glacial and periglacial permafrost [6, 22-25], both can only be seen as lithospheric components. So, due to the intellectual limitations to identify ice as a rock, it is often considered as a specific, different additional element [9], thus escaping from rigid classifications. 


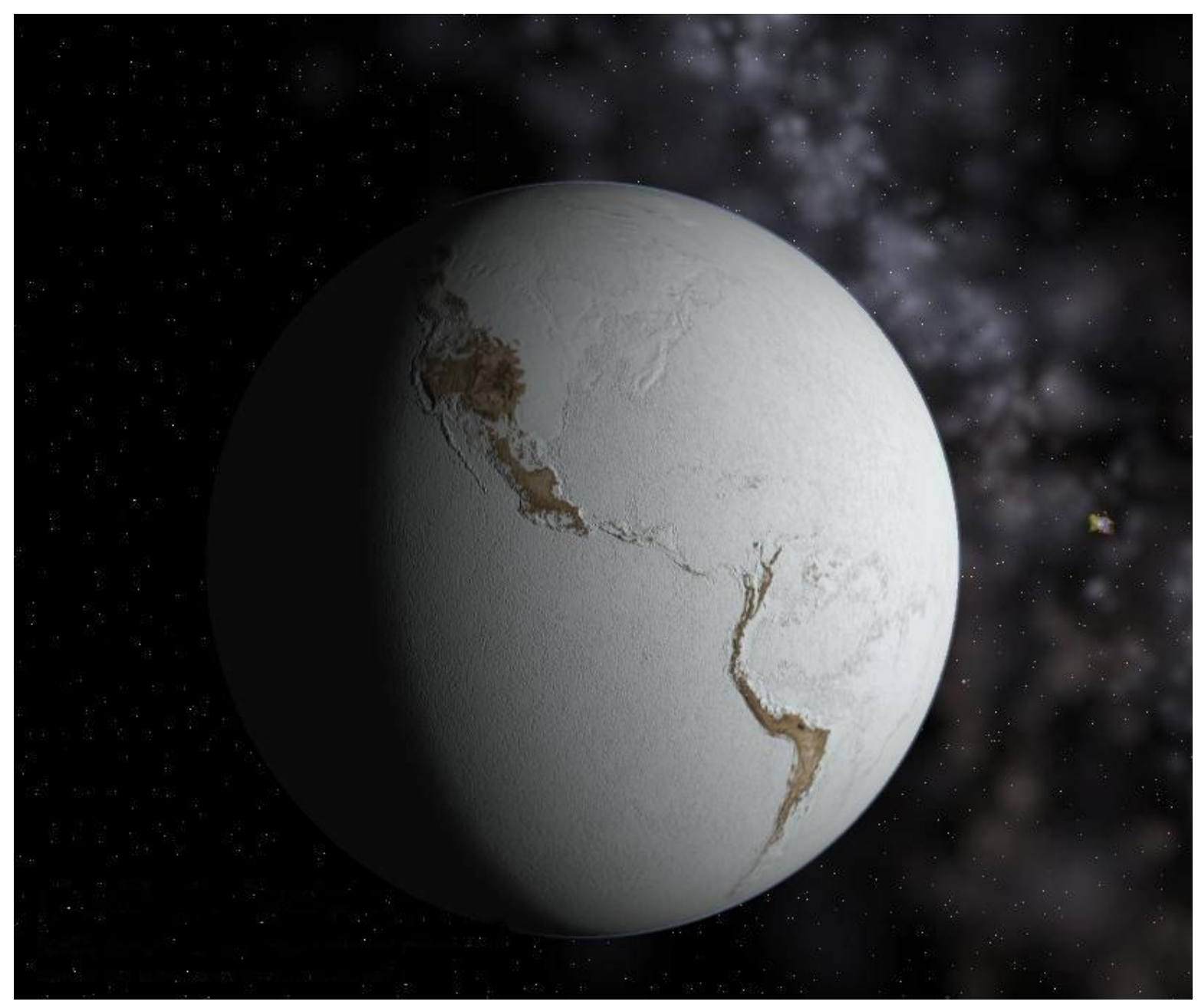

Fig.5. Fictional Snowball Earth created by Neethis. Icy area seems to be homogeneous, whereas most probable icy litosphere is that similar to icy-moons like Europe or Enceladus, with the surface indicating tectonic activity. Courtesy of Wikimedia (commons.wikimedia.org).

Set against this background, this paper presents an analogy that corrects for these inaccuracies. This analogy can be thus universal and non-contradictory, and involved the reversal of the analogy that uses the Earth as the reference for cosmic studies. After all, the Earth is also part of the Cosmos, yet the universal principles must be determined based on other planets, as the Earth shows a series of exceptional characteristics compared to that of the rest of the planets identified to date. The relatively young scientific discipline of Earth and Planetary Sciences rightly encompasses the study of all planets following the methodological principle of uniformitarianism, under the mentioned assumption that natural laws do not vary in time and space.

The most obvious argument for incorporating ice into the lithosphere derives from cosmological studies. Ice is present in many celestial bodies (Fig. 4). Among them, the icy moons represent one of the most remarkable examples. Europe, one of Jupiter's moons, is entirely covered by an ice layer and the terminology used to describe its internal structure entirely derives from geological descriptions from the Earth. The outer layer of Europa is rich in $\mathrm{H}_{2} \mathrm{O}$ and other volatiles and is known as the crust. This volatile crust is divided into a solid upper crust, known as the icy-shell, and a liquid layer below often referred to as Europa's ocean or hydrosphere. At the same time, the icy shell is divided into a cold, brittle top layer known as the lithosphere and a temperate, solid, convecting interior layer known as the asthenosphere [26]. This icy-moon structure, with an icy lithosphere, is not uncommon in the Solar System and beyond (Fig. 4). Similarly, the cryo-volcanic processes observed in Titan, another Jupiter moon, are also described using Earth processes, such as 
ice-lava, cryovolcanic eruption, etc. [27]. Ice in the lithosphere of Mars not only appears in the form of isolated polar ice domes, but also as ice-cement responsible for the lithification of rocks at a depth of up to $2.5 \mathrm{~km}$ on the equator and up to $6.5 \mathrm{~km}$ on the poles [28]. Whether running water was in geological past present in Mars remains still open fundamental question [29]. In fact, finding other types of icy-geological processes on other celestial bodies is not discarded by Earth scientists, although finding analogous icy-processes on Earth surface seems increasingly difficult, even if they should not be discarded for the Earth's lithosphere. Thus, using the correct analogy, we can study ice on Earth in the same way than that outside Earth.

To this end, we can see that the cognitive analogy currently used in comparative studies has already lost its basis. In fact, this statement is probably enough to open a new chapter in Earth sciences. Earth has become the main point of reference for planetary science, in particular through being our closest and most prolific field of information. In turn, this has led to a knowledge transfer from Earth to that from other planets. However, the latest decades of the 20th century have seen a steep increase in studies of other celestial bodies, whereby our universal context reaches beyond the Earth boundaries.

\section{Earth as an icy planet}

If one looks at Earth from an astronomical perspective, within a wider time scale than that traditionally used by Earth scientists, the need to reverse the reference point in the study of celestial bodies becomes more apparent.

In the past, the surface of Earth has changed much more spectacularly than in its recent past. Snowball Earth represents a particularly good example on the changes experienced by the Earth's surface regarding the presence of ice (Fig. 5). This planet-wide glaciation lasted approximately 200 My during the Neoproterozoic period (Cryogenian), ca. 750 to $550 \mathrm{My}$ ago [30,31]. This ice had a double origin, partly it was created by freezing, which leads to a congelation type of ice on the water surface, and which is genetically equivalent to magmatic rocks $[9,10]$. On the other hand, a cooling of the climate led further to a glaciation resulted in covering the dry lands by sedimentational and metamorphic (glacial) ice. A significant portion of oceans was covered by glacial ice analogous to our modern ice-shelves and known as a "sea glacier" due to its size [32]. The sections of lands remaining ice free were covered by permafrost. The glacierization and freezing of the Earth-crust was at this point complete, when a $3 \mathrm{~km}$-thick ice-sheet covered all the continents, with the equatorial temperatures kept below $-20^{\circ} \mathrm{C}$ and the oceans covered by a continuous ice shell hundreds of metres thick from pole to pole. The estimated mean global temperature was $-50^{\circ} \mathrm{C}$ and the mean surface temperatures were between $-80^{\circ} \mathrm{C}$ and $-110^{\circ} \mathrm{C}$ at high latitudes. In fact, there is no remarkable differences between the Earth and the surface of the icy-moons, and the surface of the Earth was virtually the same than the icy-lithosphere of the icy-moons. Under the influence of oceanic tides and other geological processes, structures such as folds, faults and cryovolcanic phenomena present in Europe or Titan could have occurred on Earth.

To this point, it is obvious that considering ice as a specific additional or complementary body (as described by A.B. Dobrowolski, [9]), something between the hydro- and the lithosphere, precludes from a correct understanding of what ice actually is, and as a consequence, preserves the uniformity in cryospheric studies.

\section{Uniformity a new rule}

Using analogues is one of the most valuable ways to know and understand processes on Earth, with all the points discussed above indicating that this analogy can work bi-directionally. Thus, if we have to maintain proper proportions, the analogy can also be reversed. Therefore, we can rule that the Earth should not be the reference point in analogous studies of the celestial bodies, for it has a 
unique status in the cosmos. It is the cosmos and the celestial bodies what constitute the reference for Earth processes, and for its geological structure. To this end, the cosmos becomes the key to understanding Earth. This principle can be called the principle of spatial uniformitarianism, as it covers all research fields within Earth and Planetary Sciences, while the Hutton-Lyell principle, the present is the key to the past, can be thereafter known as the principle of temporal uniformitarianism. These principles are complementary and encompass time and space, comprehensively defining the principle of uniformitarianism.

\section{Conclusions}

The principle of spatial uniformitarianism is illustrated here by the fact that ice and its characteristics are uniform across all celestial bodies. This allows creating a comprehensive and uniform way of understanding both the terrestrial and extraterrestrial environments, in particular by:

1. The ultimate departure from the geocentric point of view in the Earth sciences,

2. Preservation the unity of science in research conducted on Earth and on other celestial bodies.

The practical application of this principle will bring help understanding the role of ice on the surface of the Earth:

a. Ice, both on and outside Earth, should be classified as a lithospheric component, so that all the disciplines involved in its study, including cryology, glaciology, periglaciology, geology, geography and planetary science, can be fully linked.

b. Incorporating ice into the lithosphere ultimately allows for considering Antarctica as a continent, defining its boundaries and understanding the essence of the floating ice of each origin.

c. Considering ice part of the lithosphere allows encompassing glaciology and permafrost science, as thus the permafrost can be considered present in both types of lithosphere: glacial and nonglacial (periglacial).

d. The area encompassed by permafrost on Antarctica can be unambiguously defined.

e. The approaches based on this principle allow for clarifying current inconsistences and correctly understanding the presence, role and processes connected to ice on Earth.

The application of the principle of spatial uniformitarianism is not limited to these examples and the above-mentioned scientific disciplines. It may have a much wider universal reach, including other disciplines, such as hydrology or climatology, successfully used both in the Earth's environment and in the Cosmos.

Supplementary Materials: There is no supplementary materials.

Author Contributions: Author is solely responsible for the text.

Funding: Please add: This research was funded by National Science Centre (NCN) Poland grant number DEC2012/07/B/ST10/04268, AMDG.

Conflicts of Interest: The author declare no conflict of interest.

\section{References}

1. Romano, M.: Reviewing the term uniformitarianism in modern Earth sciences. Earth-Sci. Rev., 2015, 148, 65-76, doi:10.1016/j.earscirev.2015.05.010. 
2. Baker, V. R.: Planetary landscape systems: a limitless frontier. Earth Surf. Proc. Land., 2008, 33, 1341-1353, doi:10.1002/esp.1713.

3. Farr, T. G.: Terrestrial analogs to Mars: The NRC community decadal report. Planet. Space Sci., 2004, 52, 3-10, doi:10.1016/j.pss.2003.08.004.

4. Léveillé, R.: A half-century of terrestrial analog studies: From craters on the Moon to searching for life on Mars. Planet. Space Sci., 2010, 58, 631-638, doi:10.1016/j.pss.2009.04.001.

5. Dobiński, W.: The cryosphere and Glacial Permafrost as its Integral Component. Central Eur. J. Geosci., 2012., 4 (4), 623-640, doi:10.2478/s13533-012-0109-8.

6. Dobiński, W.: Ice and environment: A terminological discussion. Earth-Sci. Rev., 2006, 79, 229-240, doi:10.1016/j.earscirev.2006.07.003.

7. Jania, J.: Ice, in: A. S. Goudie, (Ed) Encyclopedia of Geomorphology 2004, vol. 1, Routlege, Taylor and Francis Group, 544-549.

8. Dobinski, W.: Kryosphere - Hydrosphere Relationship. Nova Science Publishers Inc., New York. 2011.

9. Dobrowolski, A. B.: La glace au point de vue petrographique (Essai de classification des roches de glace), B. Soc Fr. Mineral. 1931, 54 (1-2), 5-19.

10. Shumskii, P. A.: Principles of Structural Glaciology. (Dover Publications, Inc., New York Transl. D. Kraus. 1964.

11. Anderton, P. W.: .Ice fabrcs and petrography, Meserve Glacier, Antarctica. J. Glaciol. 1974, 13 (68), $285-$ 306. doi:10.3189/S0022143000023091.

12. Petersen, L. Heynen, M. Pellicciotti, F.: Freshwater resources: past present, future in: D. Richardson, N. Castree, M. F. Goodchild, A. Kobayashi, W. Liu, R. A. Marston, (Eds) The International Encyclopedia of Geography, Wiley, 2017, 1-11, doi:10.1002/9781118786352.wbieg0712,.

13. Fretwell P., Pritchard H. D., Vaughan D. G., Bamber J. L,. Barrand N. E., Bell R., Bianchi C., Bingham R. G., Blankenship D. D, Casassa G., Catania G., Callens D., Conway H., Cook A. J., Corr H. F. J., Damaske D., Damm V., Ferraccioli F., Forsberg R., Fujita S., Gim Y., Gogineni P., Griggs J. A., Hindmarsh R. C. A., Holmlund P., Holt J. W., Jacobel R. W., Jenkins A., Jokat W., Jordan T., King E. C., Kohler J., Krabill W., Riger-Kusk M., Langley K. A., Leitchenkov G., Leuschen C., Luyendyk B. P., Matsuoka K., Mouginot J., Nitsche F. O., Nogi Y., Nost O. A., Popov S. V., Rignot E., Rippin D. M., Rivera A., Roberts J., Ross N., Siegert M. J., Smith A. M., Steinhage D., Studinger M., Sun B., Tinto B. K., Welch B. C., Wilson D., Young D. A., Xiangbin C., Zirizzotti A.: Bedmap2: Improved ice bed, surface and thickness datasets for Antarctica. Cryosphere 2013, 7, 375-393, doi:10.5194/tc-7-375-2013.

14. Prăvălie, R.: Drylands extent and environmental issues. A global approach Earth-Sci. Rev, 2016, 161, 259_ 278, doi:10.1016/j.earscirev.2016.08.003.

15. Safriel, U. Adeel Z., Niemeijer D., Puigdefabregas J., White R., Lal R., Winslow M., Ziedler J., Prince S., Archer E., King C., Shapiro B., Wessels K., Nielsen T., Portnov B., Reshef I., Thonnell J., Lachman E., McNab D.: Chapter 22: Dryland Systems. Millennium Ecosystem Assessment - Ecosystems and Human Well-being. World Resources Institute, Washington DC, 2005, 623-662..

16. Williams G. E., Schmidt P. W. Young G. M.: Strongly seasonal Proterozoic glacial climate in low palaeolatitudes: Radically different climate system on the pre-Ediacaran Earth. Geosci. Front. 7, 555-571. 2016.

17. Paterson W. S. B.: The Physics of Glaciers, Third Edition. Pergamon. 1994.

18. Bindschadler R., Choi H., Wichlacz A., Bingham R., Bohlander J., Brunt K., Corr H., Drews R., Fricker H., Hall M., Hindmarsh R., Kohler J., Padman L., Rack W., Rotschky G., Urbini S., Vornberger P. Young N.: Getting around Antarctica: new high-resolution mappings of the grounded and freely-floating boundaries of the Antarctic ice sheet created for the International Polar Year, Cryosphere, 2011 5, 569-588, doi:10.5194/tc-5-569-2011.

19. Rignot, E. Jacobs S., Mouginot J., Scheuchl B.: Ice-Shelf Melting Around Antarctica. Science 2013, 341, (6143), 266-270, doi:10.1126/science.1235798.

20. Peters K.: “Oceans and seas: physical geography” in: D. Richardson, N. Castree, M. F. Goodchild, A. Kobayashi, W. Liu, R. A. Marston, (Eds) The International Encyclopedia of Geography, Wiley, 2017, 1-5, doi:10.1002/9781118786352.wbieg0541,.

21. Dobiński W.: Permafrost - definition and extent in: D. Richardson, N. Castree, M. F. Goodchild, A. Kobayashi, W. Liu, R. A. Marston, (Eds) The International Encyclopedia of Geography, Wiley 2017, 1-9, doi:10.1002/9781118786352.wbieg0277. 
22. Etzelmüller, B., Hagen, J.O.,. Glacier-permafrost interaction in Arctic and alpine mountain environments with examples from southern Norway and Svalbard. In: Harris, C., Murton, J.B., (Eds.) Cryospheric systems: Glaciers and Permafrost: Geological Society, London, Special Publications, 2005, 242, 11-27.

23. Dobinski W.: Permafrost. Earth-Sci. Rev. 2011, 108, 158-169, doi:10.1016/j.earscirev.2011.06.007.

24. Dobiński W., Grabiec M. \& Glazer M.: Cold - temperate transition surface and permafrost base (CTS-PB) as an environmental axis in glacier-permafrost relationship, based on research carried out on the Storglaciären and its forefield, northern Sweden. Quaternary Res., 2017, 88, (3), 551-569, doi:10.1017/qua.2017.65.

25. Washburn A. L., Periglacial processes and environments. Edward Arnold, London 1973.

26. Kargel J. S., Kaye J. Z., Head III J. W., Marion G. M., Sassen R., Crowley J.K., Ballestros O. P., Grant S. A. \& Hogenboom D. L.: Europa's Crust and Ocean: Origin, Composition, and the Prospects for Life. Icarus, 2000, 148, 226-265, doi:10.1006/icar.2000.6471.

27. Lopes R. M. C., Kirk R. L., Mitchell K. L., LeGall A., Barnes J. W., Hayes A., Kargel J., Wye L., Radebaugh J., Stofan E.R., Janssen M. A., Neish C. D., Wall S. D., Wood C. A., Lunine J. I. Malaska M. J.:

Cryovolcanism on Titan: New results from Cassini RADAR and VIMS, J. Geophys. Res. Planets, 2013, 118, 416-435, doi:10.1002/jgre.20062.

28. Lassue J., Mangold N., Hauber E., Clifford S., Feldman W., Gasnault O., Grima C., Maurice S., Mousis O.: Quantitative Assessments of the Martian Hydrosphere Space Sci. Rev., 2013, 174, 155-212, doi:10.1007/s11214-012-9946-5.

29. Head J. W., Greeley R., Golombek M. P., Hartmann W. K., Hauber E., Jaumann R., Masson P., Neukum G., Nyquist L. E., Carr M. H.: Geological processes and evolution. Space Sci. Rev., 2001, 96, 263-292, doi:10.1023/A:1011953424736.

30. Hoffman P. F., Kaufman A. J., Halverson G. P., Schrag D. P.: A Neoproterozoic Snowball Earth. Science 1998, 281 (5381), 1342-1346.

31. Macdonald F. A., Schmitz M. D., Crowley J. L., Roots C. F., Jones D. S., Maloof A. C., Strauss J. V., Cohen P. A., Johnston D. T., Schrag D. P.: Calibrating the Cryogenian. Science 2010, 327, (5970), 1241-1243, doi:10.1126/science.1183325.

32. Goodman J. C. Pierrehumbert R. T.: Glacial flow of floating marine ice in "Snowball Earth," J. Geophys. Res. 2003, 108 (C10), 3308. doi:10.1029/2002JC001471. 